\title{
The Realization of the Design and Processing of Ladies' Shoes Pictures on Web
}

\author{
Xia Zhi-Liang ${ }^{1}$, Tian Qi-Ming ${ }^{2}$ \\ Wenzhou Vocational \& Technical College, Wenzhou. 325035 \\ Xia441@sina.com
}

Keywords: picture; take pictures; TMALL template; procedure; commodity display

\begin{abstract}
This thesis take pictures for the products and processed the pictures that need to be uploaded, combine the relative features of Josiny ladies' shoes and the requests for the commodity display pictures that come up on by TMALL, make the product template that is up to the requests of TMALL and the display of products (up load the pictures); introduce the overall process of picture processing with the use of professional digital single lens reflex and the application of some relevant design software; upload the final effect picture to the web and introduce the operation of relevant processes.
\end{abstract}

\section{Introduction}

According to the unique features of the shoes, the market trend of ladies' shoes, the requests of TMALL activities and the directions of the chief designer of the company, all side of the shoes and unique details are taken through adjust the light effect and the shooting angle. Then process the pictures with white background and keep the inverted image of the shoes by using the CAD software such as Photoshop and AI according to the commodity; next make the template of TMALL pictures, display the commodities and post the information of product. Finally, compose the position of the products.

\section{The Processes of Shooting, Processing and Composition of the Products}

Nowadays, because convenient and efficient of online shopping, more and more people especially young students and white-collar employees prefer the low-cost online shopping along with social progress and the gradually-matured electronic technology. There are many online shopping platforms such as TMALL, Taobao and Jingdong shopping mall. The buyers arouse their buying inclination by knowing the product information through pictures and text descriptions. Sellers introduce all kinds of information such as the date of manufacture and the material quality, the specification and purpose of products to buyers through pictures and words. So pictures and words are very important to both sellers and buyers.

\subsection{The Shooting of Products}

The main characteristics of products should be known while shooting. The main products of the company are Josiny ladies shoes. Josiny 11Aj3073 is mainly elaborated in this thesis. First of all, the major details should be known to help the photographer to pay attention to the details. It is showed in picture 1. 


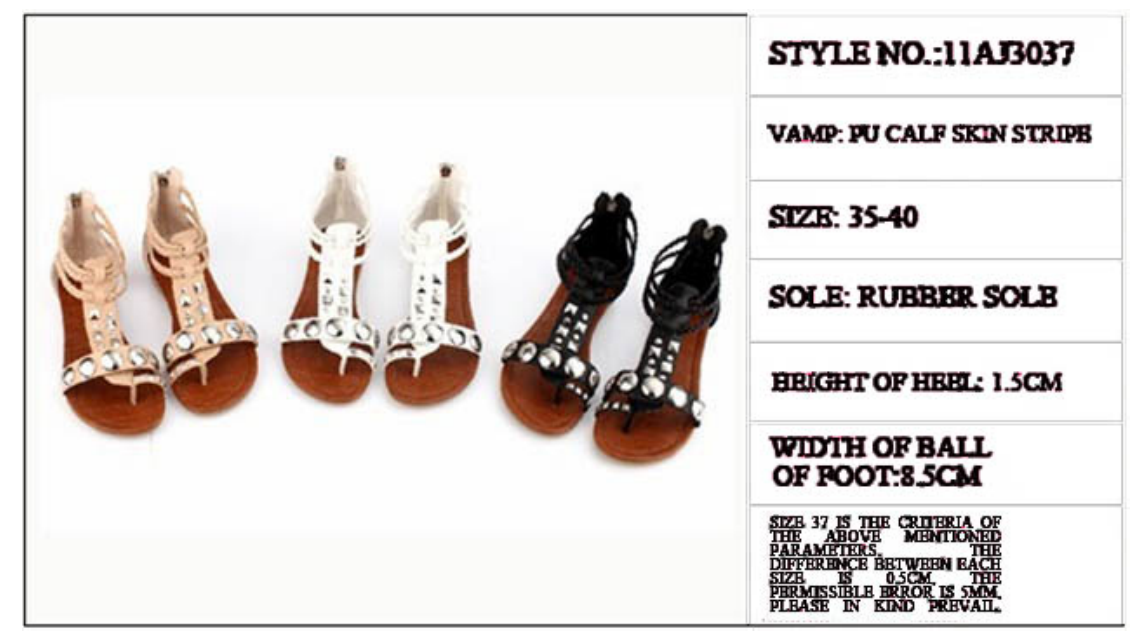

Picture 1The Major Details of 11AJ3037

Then the pictures should be taken. High-qualified light can make picture clearer, so the light in the studio should be adjusted to the best condition before shooting. The focal distance of the camera should focus on the brightest shot of the shoes (as is showed in picture 1, the main bright shots are rivets, the hand-weaved stripes and so on). On the TMALL page, the first picture customers see is window display picture (every view point should be showed in the picture). So every view point of the shoes for shooting should be set while shooting. The main view points of shoes are: 45-degree, toe cap to left, toe cap to right, hell, vamp, sole, 45-degree of every color and the integrated picture of every color. It is showed in picture 2. The shoes in the pictures are 11AJ3037.

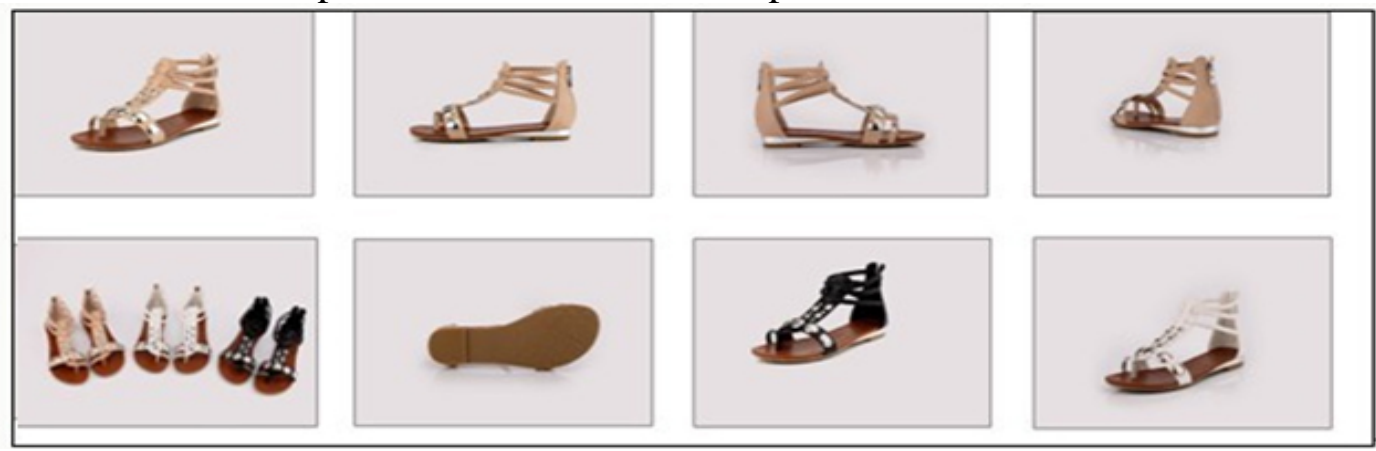

Picture 2 Window Display Picture

The integrated picture of every color (3-5 pictures of each color) is showed in picture 3 .

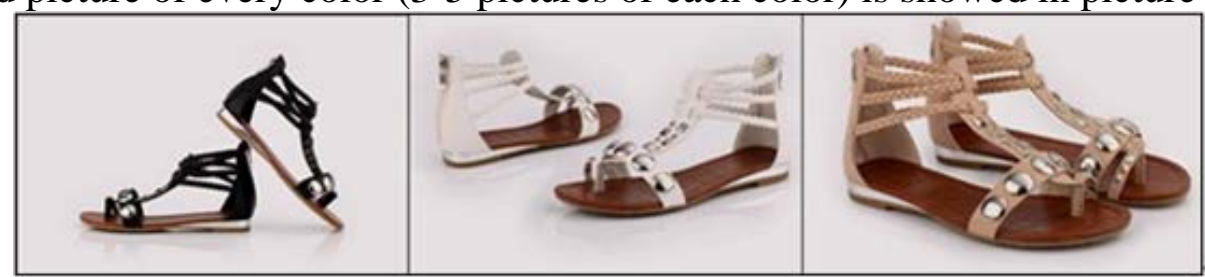

Picture 3 Integrated Picture

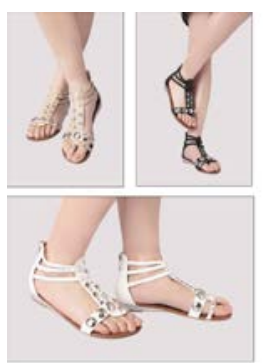

Picture 4 Picture with Model 
Professional models are hired by the company in order to enrich the webpage. So , picture with model should be taken at last( 2-3 pictures should be taken for each color. Every characteristic and point of view should be showed sufficiently by the model's action). It is showed in picture 4 .

\subsection{Picture Processing}

Photoshop will be used for picture processing after the shooting. Step 1: Copy a layer and build a layer with white background. Step 2: Differences will be caused because the original picture is greening or bluing, as is showed in Picture 5,wipe off cyan and blue with the tools of hue tool and saturability tool (decrease the saturability of cyan and blue to -100 , and increase the lightness to +100 ). It is showed in picture 5 .
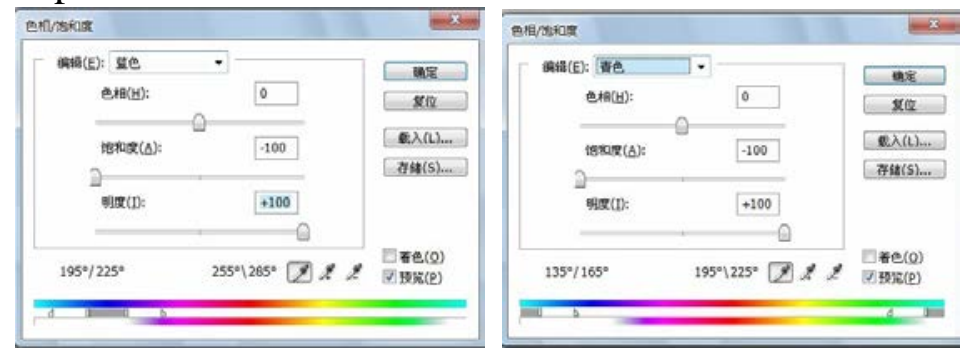

Picture 5 Wipe of Cyan and Blue

Then wipe off the background color with the cutout tool, but keep the shoes' sense of reality, the inverted image must be kept. There are many kinds of cutouts, because there are many pictures of a certain pair of shoes, several kinds of cutouts should be utilized. The background of the shoes is decided by the characteristics and the color of the shoes.

There are three colors of 11AJ3037 (hereinafter 3037): apricot, black and white. For the styles of black and apricot, magic stick can be utilized to wipe off the background color. Then, color dodge tool should be used to dodge the inverted image of shoes gradually. For the style of white, the method of gallery can be used for cutout. First, copy a gallery with strong contrast of light and shade to show the layering of the shoes' inverted image and make the picture more real. Then check if there are some blemishes such as trace of glue and obvious splits, if so, the seal tool or brush repairing tool must be used to embellish the shoes. It is showed in Picture 6 .

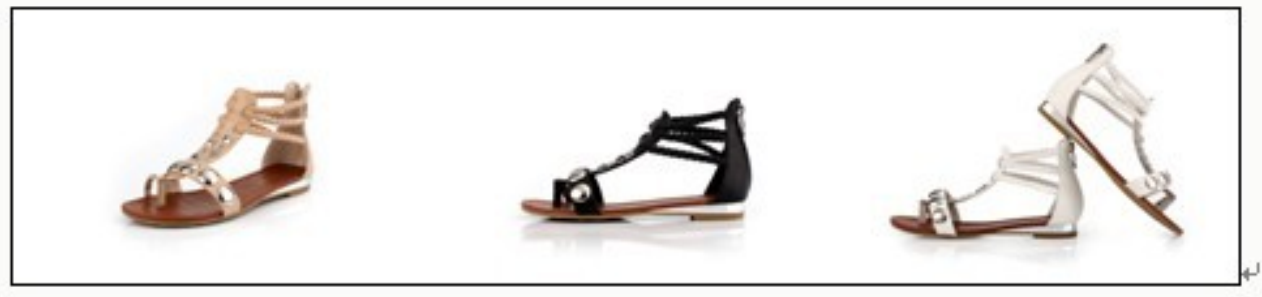

Picture 6 Processed Pictures

Finally, the picture with model should be processed. Step 1: wipe off the background, then sketch the section should be buffed with the pen tool. Step 2: buff the blemishes of the model's legs with the Neat Image in Filter to make the legs of the model smoother and the picture looks milder. The Neat Image is portraiture, not the Neat Image comes with the cutout software Photoshop, but a filter plugin should be downloaded from websites. The processed picture with model is showed in Picture 7. 

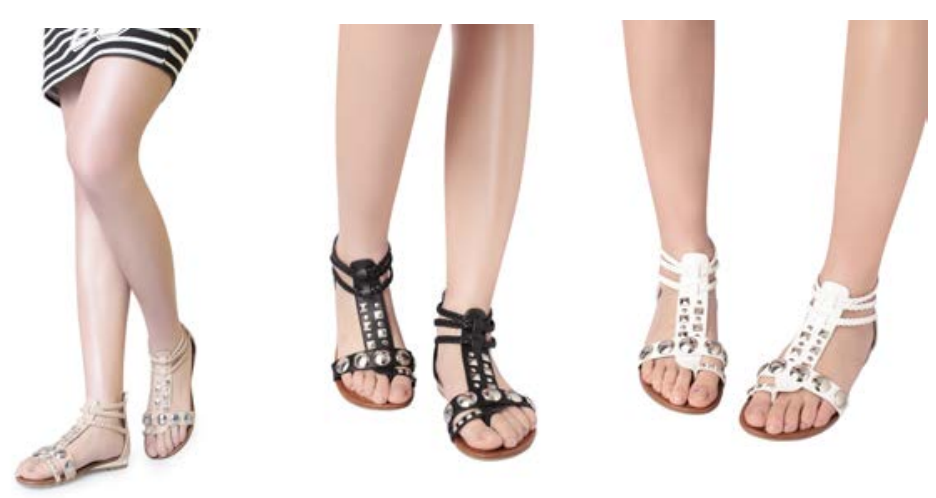

Picture 7 Processed Pictures with Model

\subsection{Template making}

Introduce the parameter of the production (including the style number, shell fabric, sizes of the shoes, the material and quality of sole, the height of the heel and the width of the ball of the foot). Some people think it is useless to measure the width of the ball of foot. Actually, this is not true. Because the heights of insteps are different from people to people, the width of the ball of foot must be measured. If the ball of foot of a customer is high (there are more muscle on insteps), standard-sized shoes will make the forepart of the foot feel crowded and uncomfortable. So a bigger size of shoes will be suggested for the customer. It is showed in Picture 8.

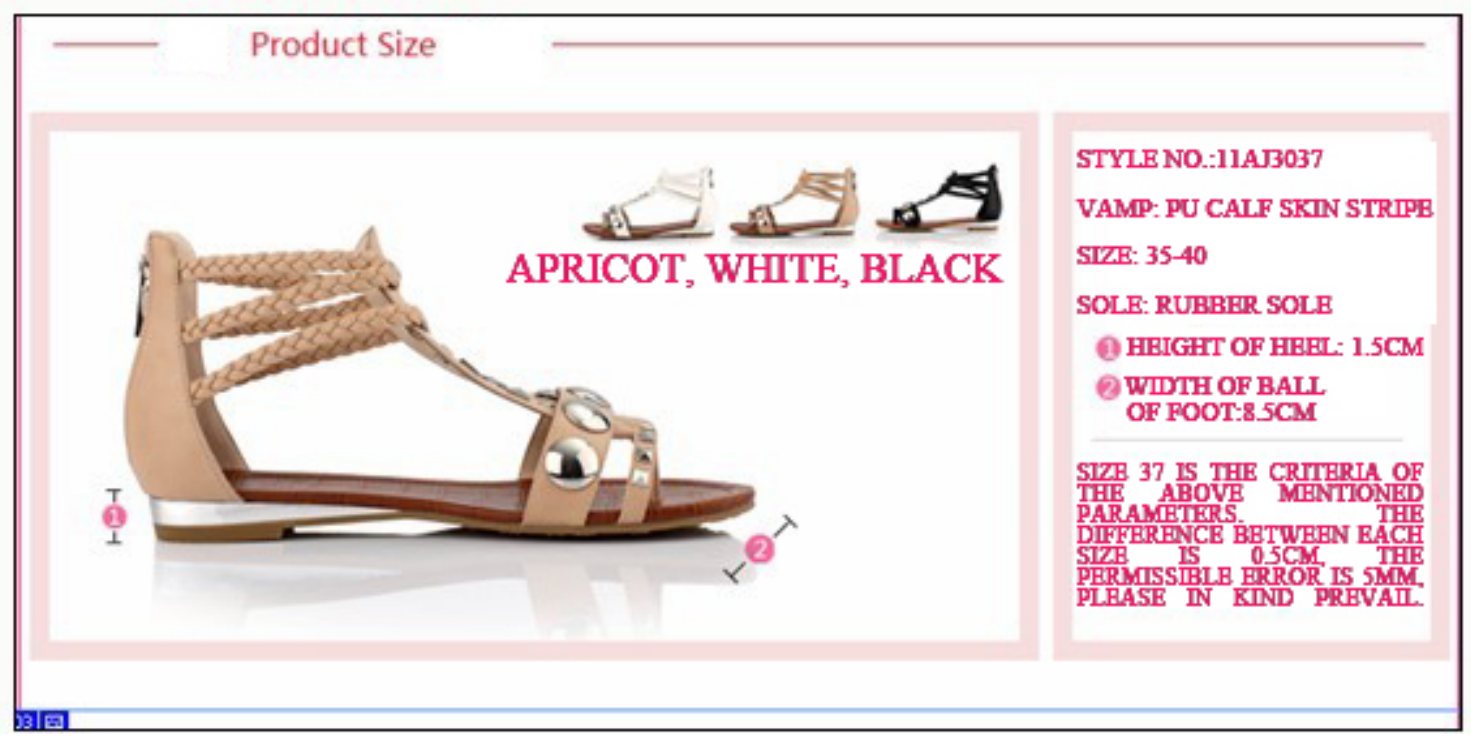

Picture 8 Template

The occasions that the template is not long enough are encountered occasionally while making the template, so the canvas should be increased. If the canvas is too long, the spare parts should be trimmed with knife tool. To offer the customers the appearance the shoes are worn, step 4 should be make the pictures with models. It is showed in Picture 9. 


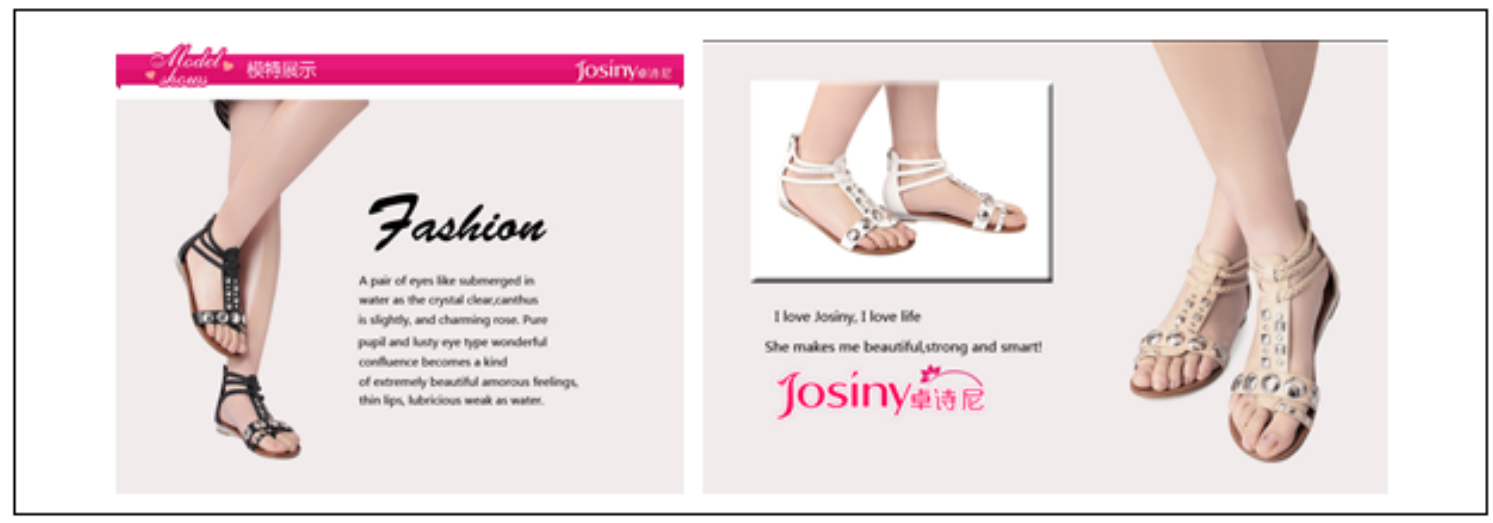

Picture 9 Pictures with Models

To offer agreeable shoes for customers, we should inform the indeed sizes for customer, the brand stories of Josiny, and the buying criteria. The content of the buying criteria should contain the following information: the issues about goods delivering, the issues that required attention while signing the shoes. The conflicts between customers and couriers and complains of shops' issues of honesty may be caused because the customers don't know the buying criteria. The following 3 pictures showed in Picture 10 should be added to offer tips that called by a joint name kind remind.

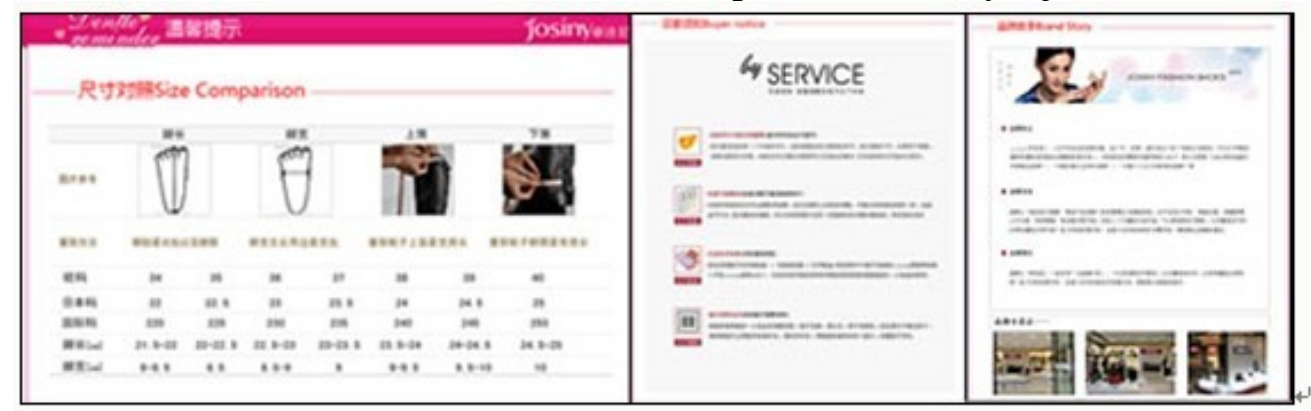

Picture 10 Kind Remind

The usually-used templates are made. To make the new customers know the sell condition and the comments from other customers of this style of shoes during activities, a picture with the sell condition of this style of shoes and the comments record should be added.

Save the pictures as Web format, the saving type should be HTML and Image in order to offer convenient while product display. The last step is to make the window display pictures. There should be 8-10 window display pictures including 45-degree, toe cap to left, toe cap to right, hell, vamp, sole, 45-degree of every color and the integrated picture of every color. Tips: the pictures should be less than 500k (follow the rules of TMALL). The specification of window display pictures is $1500 * 1500$, generally with white background. Selling points can also be added during activities. It is showed in Picture 11. 


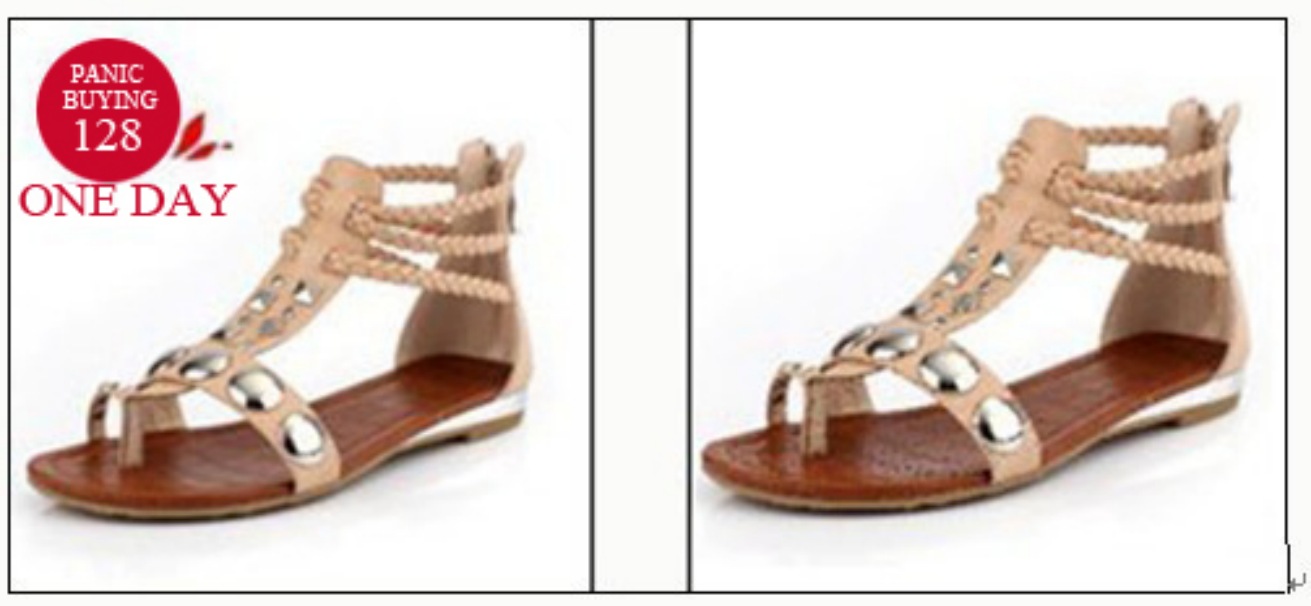

Picture 11 The Window Display Picture During Activities and the Usually-showed Window Display Picture

\section{The Uploading of Pictures and the Latter Follow Up}

Product Display. After the templates are made, we can display the commodity. Step 1: $\log$ in TMALL. Step 2: Click TMALL. Step 3: Upload the pictures, click sellers' tool. Then click TMALL Album Management. Step 4: Click Sort Management, then build a document, add pictures (tips: add the template pictures). Step 5: Click Commodity Management, post new commodity.

\section{Conclusion}

The above mentioned information is the process from shooting to final effect picture of shoes. Pictures can be linked to TMALL shopping mall after their uploading. We can also investigate how people like the description of the commodity, then make customers' favorable templates. The templates should also mater the requests of TMALL shopping mall, if not, TMALL will have the right to punish the shop such as reduce the reputation grade, if the case is serious, TMALL will close the operation of the shop. So the specification of pictures and the format of templates are very important. Sometime, customers complain that the picture showed on the internet is not the same with the commodity, this is because the screens of each computer is not the same or the different light points of each angel. For the above mentioned conditions, good communication with customers should be down to solve practical problems.

\section{Fund program}

Zhejiang higher vocational colleges young and middle-aged professional leaders' professional leading project (lj2013043) ; 2011 Zhejiang planning project on educational technology research (JB078)

\section{References}

[1] Yong Deng. < Brief Discussion of Design Overall Arrangement and Principle> [J] The Journal of Western Chong Qing University (Edition of Natural Science), 2011, (03): 32-34

[2] Hong Luo. <The Application of Photoshop Cutout Techniques in Image Processing> [J] Journalism Lover, 2012, (20): 149-150 
[3] Lijuan Jia <The Adjustment of Image Resolution in Photoshop> [J] Print Field 2010, (03): $52-53$

[4] Hongzheng Sun. <Random Talk of the Accuracy of Manual Focus of Digital Single Lens Reflex> [J] Camera 2014, (12) : 16.

[5] Yongming Zhu. <The Shape, Symbol and Language in Visual Communication Design> [J] Journal of Nanjing University of Arts (The Edition of Art and Design 2014, (01): 58-62 